The presenting features in symptomatic cases are now well established. ${ }^{14}$ After reports of dramatic neurological and biochemical responses to biotin, it is disappointing that sensorineural deafness has been recognised in about half the known cases of biotinidase deficiency. ${ }^{5}$ Visual impairment is reported less often and may be due to optic atrophy ${ }^{1}$ or severe myopia with possible retinal epithelial dysplasia. ${ }^{5}$ The cause of the auditory and visual impairments remains unclear. Treatment with exogenous biotin would not be expected to prevent the continued accumulation of biocytin, and it has been suggested that this and larger biotinyl peptides might be ototoxic. ${ }^{6}$ In the present patient, it was possible to confirm normal vision and hearing before biotin treatment, but monitoring will continue throughout childhood.

The infant in this report was not treated until the diagnosis had been confirmed on three samples taken at intervals of two weeks. Since it is presumed, however, that symptoms are only evident when a baby with biotinidase deficiency has used up all possible sources of endogenous biotin, treatment should perhaps ideally be given as soon as the diagnosis has been made. Although it seems that biotinidase does not cross the placenta, there is little justification for prenatal diagnosis, since good pro- gress is being made in the present patient whose treatment was started just before the age of 11 weeks.

I thank Dr M Maguire, Merthyr Tydfil, Dr K Bartlett, Newcastle upon Tyne, Mr P A Graham, Mr R G Mills, and Dr D Stansbie of this hospital.

\section{References}

${ }^{1}$ Wolf B, Grier RE, Allen RJ, et al. Phenotypic variation in biotinidase deficiency. $J$ Pediatr 1983;103:233-41.

2 Charles BM, Hosking G, Green A, Pollitt R, Bartlett K, Taitz LS. Biotin-responsive alopecia and developmental regression. Lancet 1979;ii:118-20.

3 Wolf B, Grier RE, Parker WD, Goodman SI, Allen RJ. Deficient biotinidase activity in late-onset multiple carboxylase deficiency. $N$ Engl $J$ Med 1983;308:161.

4 Schubiger G, Caflisch U, Baumgartner R, Suormala T, Bachmann C. Biotinidase deficiency: clinical course and biochemical findings. J Inher Metab Dis 1984;7:129-30.

5 Taitz LS, Green A, Strachan I, Bartlett K, Bennet $M$. Biotinidase deficiency and the eye and the ear. Lancet 1983;ii:918.

6 Wolf B, Grier RE, Heard GS. Hearing loss in biotinidase deficiency. Lancet 1983;ii:1365-6.

Correspondence to: Dr S J Wallace, Department of Paediatric Neurology, University Hospital of Wales, Cardiff CF4 4XW.

Received 5 February 1985

\title{
Acute lymphoblastic leukaemia presenting with raised intracranial pressure
}

\author{
N H RUSSELL, I J LEWIS, AND J MARTIN \\ Regional Unit of Paediatric Haematology and Oncology, Department of Child Health, Alder Hey Children's \\ Hospital, Liverpool
}

\begin{abstract}
SUMMARY A child presented with raised intracranial pressure for which no cause was established. Five months later a further cerebrospinal fluid examination showed lymphoblasts expressing the common acute lymphoblastic leukaemia phenotype. Bone marrow infiltration was not present. This case illustrates the difficulties that may be encountered in establishing the diagnosis of central nervous system leukaemia.
\end{abstract}

The central nervous system is a common site of relapse of childhood acute lymphoblastic leukaemia.
These patients frequently present with features of raised intracranial pressure and excessive weight gain-the 'hypothalamic syndrome'. 'The diagnosis is usually made on clinical grounds and by the presence of lymphoblasts in the cerebrospinal fluid, although occasionally no cellular infiltrate is found. ${ }^{1}$ We describe a child presenting with features typical of central nervous system leukaemia in whom the diagnosis was not initially established due to the absence of leukaemic cells in the cerebrospinal fluid or peripheral blood.

\section{Case report}

A 10 year old boy presented with a six week history 
of frontal headache, vomiting, blurred vision, and ataxic gait with a tendency to fall to the right. Physical examination showed papilloedema, bilateral VI cranial nerve palsies, generalised limb weakness, and symmetrically diminished limb reflexes. The peripheral blood count and white cell differential count were normal; haemoglobin was $11.8 \mathrm{~g} / \mathrm{dl}$; white cell count $10.8 \times 10^{9} / \mathrm{l}$; platelets $260 \times 10^{9} / 1$; and differential white cell count: neutrophils $9.4 \times 10^{9} / 1$, lymphocytes $1.3 \times 10^{9} / 1$, monocytes $0 \cdot 1 \times 10^{9} / 1$. A skull radiograph showed some splaying of the coronal suture with loss of definition of the anterior aspect of the dorsum sellae consistent with raised intracranial pressure. Two cerebral computed tomograms were performed and showed no abnormality. Other investigations including a myelogram, nerve conduction studies, blood lead estimation, and urinary delta amino laevulnic acid excretion were all normal. Examination of the cerebrospinal fluid showed a raised protein value at $6 \mathrm{~g} / 1$, but a normal glucose concentration $(4.5 \mathrm{mmol} / \mathrm{l})$ and normal white cell count $(2 / \mu l)$. A cytospin examination of the cerebrospinal fluid showed only a few neutrophils and lymphocytes. Bacterial and acid fast cultures were negative. No definitive diagnosis was made.

The raised intracranial pressure was treated symptomatically with a four week course of dexamethasone ( $8 \mathrm{mg} /$ day) which alleviated the headache and ataxia. The patient was observed regularly as an outpatient and two further computed tomograms were performed; both were normal. Four months after the initial presentation the symptoms of headache and vomiting recurred. Physical examination now showed early optic atrophy, grossly reduced visual acuity, and proptosis of the right eye. He had had an excessive weight gain of $10 \mathrm{~kg}$ in the previous four months. A lateral skull radiograph showed complete erosion of the pituitary fossa with diastasis of the coronal suture but a further computed tomogram was again normal. A second cerebrospinal fluid examination showed a turbid fluid with a raised protein concentration $(5 \mathrm{~g} / \mathrm{l})$, a decreased glucose concentration $(1.5 \mathrm{mmol} / \mathrm{l})$, and a white cell count of $3090 / \mu$ l. Cytologic examination indicated that most of the cells were lymphoblasts.

Surface marker analysis of the cerebrospinal fluid blasts was performed. More than $90 \%$ of the cells expressed the phenotype of common acute lymphoblastic leukaemia ${ }^{2}$ (cALL+; TdT $\left.+\mathrm{Ia}+\right)$. Other laboratory investigations included: haemoglobin $14.3 \mathrm{~g} / \mathrm{dl}$, white cell count $6 \times 10^{9} / \mathrm{l}$, and platelets $242 \times 10^{9} / 1$. The differential white cell count was normal with no blasts present. Bone marrow aspirate and biopsy showed a normocellular marrow with no evidence of leukaemia. Surface marker analysis of the bone marrow showed the complete absence of TdT + cALL+cells.

The patient was treated with remission induction therapy according to the Medical Research Council UKALL VIII schedule for acute lymphoblastic leukaemia presenting with central nervous system involvement; this included intrathecal methotrexate followed by craniospinal irradiation ( $24 \mathrm{~Gy}$ ). Treatment was accompanied by the rapid relief of symptoms and an improvement in gait and visual acuity. Lymphoblasts disappeared from the cerebrospinal fluid. The patient remains in continuous complete remission on standard maintenance treatment 24 months after diagnosis.

\section{Discussion}

This child had an unusual presentation for common acute lymphoblastic leukaemia and the diagnosis proved difficult. The initial presentation was with a six week history of symptoms of raised intracranial pressure. At that stage examination of the cerebrospinal fluid showed no cellular infiltrate, although there were minor biochemical abnormalities. The correct diagnosis was only established five months later after a second cerebrospinal fluid examination showed large numbers of common acute lymphoblastic leukaemia positive, TdT positive lymphoblasts. At this stage there was no evidence of bone marrow infiltration either by morphological or immunological analysis.

Evidence of central nervous system involvement at presentation is found in about $5 \%$ of children with acute lymphoblastic leukaemia, and it is frequently associated with a high peripheral blast cell count. ${ }^{3}$ This patient is unusual in that he developed features of central nervous system leukaemia in the absence of identifiable lymphoblasts in the cerebrospinal fluid or in the peripheral blood.

Despite the finding of a normal peripheral blood and white cell differential count, we cannot exclude the possibility of bone marrow involvement by acute lymphoblastic leukaemia at the initial presentation, and can only surmise that this child may have had purely extramedullary disease. Steroids alone can induce a remission in approximately $50 \%$ of these children ${ }^{4}$ and it is possible that the four week course of dexamethasone given to relieve the symptoms of raised intracranial pressure could have induced a bone marrow remission. Despite these reservations, this case raises interesting questions concerning the nature of extramedullary leukaemia which is normally regarded as occurring secondary to haematogenous spread which in this particular case was never documented. 
This patient illustrates that neurological problems can occasionally be the presenting feature of acute lymphoblastic leukaemia. The diagnosis of central nervous system leukaemia should be considered in cases of unexplained raised intracranial pressure or cranial nerve palsies, even in the absence of a cerebrospinal fluid infiltrate. In these cases a thorough and if necessary repeated examination of the cerebrospinal fluid is required, which should include membrane marker studies, as it was only these diagnostic techniques that enabled us to make a precise diagnosis in this case.

We thank Dr M Greaves, Imperial Cancer Research Fund Laboratories, London for help in performing the cell marker studies.
References

${ }^{1}$ Hardisty RM, Norman PM. Meningeal leukaemia. Arch Dis Child 1967;42:441-7.

2 Greaves MF, Janossy G, Peto J, Kay H. Immunologically defined subclasses of acute lymphoblastic leukaemia in children: their relationship to presentation features and prognosis. $\mathrm{Br} \mathrm{J}$ Haematol 1981;48:179-97.

${ }^{3}$ Sullivan MP, Vietti TJ, Fernbach D, Griffith KM, Haddy TB, Watkins TL. Clinical investigations in the treatment of meningeal leukaemia: radiation therapy regimes vs conventional intrathecal methotrexate. Blood 1969;34:301-19.

4 Goldin A, Sanberg JS, Henderson ES, Newman JW, Frei E III, Holland JF. The therapy of human and animal acute leukaemia. Cancer Chemotherapy Reports 1971;35:309-15.

Correspondence to Dr N H Russell, Department of Haematology, City Hospital, Nottingham NG5 1PB.

Received 15 February 1985

\title{
Investigation of the 'satisfying' quality of infant formula milks
}

\author{
O G BROOKE AND C WOOD
}

Department of Child Health, St George's Hospital, London

SUMmaRY The 'satisfying' quality of a typical, current formula milk was compared with that of an earlier type with higher protein and mineral content in a double blind, cross over trial in 10 infants. There were no significant differences in the amount of crying or volume consumed which meant that there was a higher sodium and protein intake but no associated improvement in 'satisfaction'.

Feeding problems in infancy are among the most common encountered in baby clinics and paediatric departments. Many infants seem dissatisfied with their feeding and cause distress by their frequent crying. Although this kind of behaviour often results from a variety of different disturbances of mothering, it is usually perceived by the mother to be a problem of inadequate or unsuitable feeds. She therefore changes the type of feed, often several times, ${ }^{1}$ sometimes encouraged in this by professional health workers. There is also a ground swell of opinion, unreferenced but recognised by all who work in the field, that the older infant formula milks were more satisfying than the current highly modified low solute formulas, perhaps because of their higher protein content, or because their protein was predominantly casein. With this in mind we designed a study to investigate infant feeding behaviour on two different formulas, one an example of current manufacturing practice and one from the previous generation-safely low in solute content but still containing notably more protein (mainly casein) and electrolytes than is the current fashion.

\section{Patients and methods}

Infants. Ten infants were studied in a double blind, cross over experiment. The infants were term and of normal birthweight. They were recruited on the postnatal ward on the basis that their mothers wanted to bottle feed them and were willing to take part in the study. Their mothers gave fully informed consent and the study had ethical approval. The infants were started on one or other of the trial formulas before discharge home.

Formulas. Details of the two formulas are given in Table 1 . They were supplied as ready to feed liquid preparations in containers marked only with a week number (from 1 to 8). Unconsumed feed was retained for measurement so that daily intakes could be calculated. 